\title{
Varicose Vein of Lower Extremities with Inflammation
}

National Cancer Institute

\section{Source}

National Cancer Institute. Varicose Vein of Lower Extremities with Inflammation. NCI

Thesaurus. Code C35115.

Inflammation of enlarged and tortuous veins in the hip, thigh, leg and/or foot. 